\title{
Extração e caracterização de compostos do resíduo vegetal casca de café
}

Michel Rocha Baqueta michel rb01@hotmail.com Paraná, Campo Mourão, Brasil

Jéssica Thais do Prado Silva jessicathais92@gmail.com Universidade Tecnológica Federal do Paraná, Campo Mourão, Brasil

Thaysa Fernandes Moya Moreira thaysa.mova@gmail.com Universidade Tecnologica Federal do Paraná, Campo Mourão, Brasil

Edmilson Antonio Canesin prof.canesin@gmail.com Universidade Tecnológica Federal do Paraná, Apucarana, Brasil

Odinei Hess Gonçalves odinei@utfpr.edu.br Universidade Tecnológica Federal do Paraná, Campo Mourão, Brasil

Adriele Rodrigues dos Santos adrielesantos@hotmail.com

Universidade Estadual de Maringá, Maringá Paraná, Brasil

\section{Aline Coqueiro}

alinedqi@gmail.com

Universidade Tecnológica Federal do Paraná, Campo Mourão, Brasil

Bogdan Demczuk Junior bdjunior@gmail.com

Universidade Tecnológica Federal do

Paraná, Campo Mourão, Brasil

Fernanda Vitória Leimann evitoria@gmail.com Universidade Tecnológica Federal do Paraná, Campo Mourão, Brasil

\begin{abstract}
RESUMO
A quantidade de resíduos gerados durante o beneficiamento do café no Brasil (principalmente casca) representa aproximadamente 50\% da produção. Visando diminuir este problema, o objetivo deste trabalho foi obter diferentes extratos das cascas de café, avaliar sua composição e atividade antimicrobiana. Utilizando extrações por Soxhlet, com solventes de diferentes polaridades e seletividades e analisando estes extratos por Cromatografia Gasosa acoplada à Espectrometria de Massas e Espectroscopia de Infravermelho com Transformada de Fourier, foi possível observar que os extratos diferiam em composição química e que apenas clorofórmio e diclorometano foram capazes de extrair a cafeína, devido a seletividades destes solventes. Os componentes hidrofílicos foram extraídos utilizando diferentes proporções de etanol e água, a temperatura ambiente e a $40^{\circ} \mathrm{C}$. A cafeína presente nestes extratos foi quantificada por Cromatografia Líquida de Alta Eficiência. A mudança na composição do solvente e temperatura não alteraram a composição química dos extratos, porém alteraram a quantidade de cafeína extraída. Nenhum dos extratos testados demonstrou atividade contra os microrganismos Salmonella typhimurium (ATCC 14028), Escherichia coli (ATCC 25922), Staphylococcus aureus (ATCC 25923), Pseudomonas aeruginosa (ATCC 27853) e Bacillus cereus (ATCC 14579). Pode-se concluir que as cascas de café apresentam grande potencial para a extração de cafeína, agregando valor a este resíduo vegetal e contribuindo para o aproveitamento dos resíduos produzidos no beneficiamento do café, o que diminuiria o impacto ambiental gerado pelo descarte destes.
\end{abstract}

PALAVRAS-CHAVE: casca de café; extrato oleoso; extrato hidroetanólico; cafeína; resíduos vegetais. 


\section{INTRODUÇÃO}

No Brasil, maior produtor e exportador mundial de café além de segundo maior consumidor do produto, são cultivadas duas espécies de café, a Coffea arabica e a Coffea canephora. Também são conhecidas como café arábica e café robusta ou conilon, respectivamente, e a área plantada no país corresponde a 2.251.968,2 hectares. Do total de sacas produzidas no Brasil que é de aproximadamente 20 milhões, cerca de $46,25 \%$ são destinadas ao consumo interno. Com relação à produção mundial, o Brasil é responsável por $30 \%$ do mercado internacional (USDA, 2015; ABIC, 2016; BRASIL, 2016).

O processamento do café pode ser realizado por dois métodos, sendo a via seca e a via úmida, gerando diferentes tipos de resíduos. O processo em via úmida consiste no uso de água para retirada da casca e polpa do fruto, seguida pela secagem e produção do café denominado pergaminho, dando continuidade as demais etapas durante o beneficiamento. Já no processo em via seca, uma técnica mais simples, a secagem é realizada diretamente nos grãos, ao contrário da via úmida, gerando o café em coco para o beneficiamento posterior (YOSHIDA, 2005).

Na despolpa por via seca, a principal via de produção de residuo é a retirada das cascas. O resíduo obtido além da casca, possui também a polpa e o pergaminho. Quando a despolpa é realizada por via úmida, o resíduo inicial é composto por polpa e casca, e após a secagem dos grãos, são retirados os pergaminhos, presentes em $12 \%$ dos frutos secos colhidos, originando ainda mais resíduos (BRUM, 2007).

De acordo com Fernandes (2007), Brum (2007), Lima et al. (2013) e a Companhia Nacional de Abastecimento (CONAB, 2016), com base nos processos utilizados para o beneficiamento dos grãos de café, o principal método utilizado no Brasil é por via seca, tendo elevado potencial na geração de resíduos agroindustriais, que ao serem dispostos inadequadamente, podem afetar o meio ambiente, causando a poluição de solos e águas.

Os grãos de café são constituídos pelo epicarpo (casca), mesocarpo (polpa ou mucilagem), endocarpo (pergaminho) e película (BRUM, 2007). No beneficiamento dos grãos, a quantidade de resíduo (casca) constitui aproximadamente $50 \%$ da produção, isto é, a quantidade de café beneficiado é similar à quantidade de resíduos gerados por meio do beneficiamento (ZOCA, 2012). Dessa forma, considerando que na safra de 2015 foram beneficiadas 43,24 milhões de sacas de café (CONAB, 2016), estima-se que foram gerados aproximadamente 2,58 milhões de toneladas de cascas de café.

As cascas do café, provenientes do método de via seca, caracterizam-se por sua riqueza em nutrientes e metabólitos secundários, incluindo substâncias como cafeína, taninos e polifenóis (FERNANDES, 2007). Analisando a composição química da casca de café, Brand et al. (2000) obtiveram: 11,98\% de umidade, $31,86 \%$ de fibras, $26,50 \%$ de açúcares totais, $1,50 \%$ de lipídeos, $6,03 \%$ de cinzas, $11,70 \%$ de proteína, $9,30 \%$ de taninos e $1,20 \%$ de cafeína. De acordo com os a literatura, percebe-se que os dados apresentam certas variações na quantificação dos constituintes das cascas de café, sendo que as diferenças, segundo Yoshida (2005), podem ser vinculadas as diferentes composições das espécies analisadas e por se tratar de um resíduo industrial proveniente de processamentos e 
armazenamentos diferentes, importante fator de alteração na composição química das cascas de café.

Segundo Gonçalves et al. (2005), alguns extratos vegetais apresentam substâncias com propriedades antimicrobianas, encontrando-se entre estas, os compostos fenólicos e os alcaloides. Muitos compostos fenólicos apresentam atividade antimicrobiana em algum tipo de microrganismo (ALMAJANO et al., 2008). Entre os compostos fenólicos presentes nos grãos de café, estão os ácidos hidroxicinâmicos, sendo estes os componentes majoritários desta matriz. $\mathrm{O}$ ácido hidroxicinâmico mais comumente encontrado nos grãos de café é o ácido clorogênico (ANDRADE, 2011).

A cafeína (1,3,7-trimetilxantina), um alcaloide do grupo das xantinas, presente no café, apresenta atividades biológicas importantes, como atividade antioxidante e antimicrobiana (ANDRADE, 2011), e estimulante. Fardiaz (1995) avaliou o efeito de extratos de café em diferentes concentrações sobre o crescimento de alguns microrganismos, incluindo bactérias Gram-positivas e Gram-negativas, bolores e leveduras. Entre os microrganismos avaliados, a cafeína contribuiu para a atividade antimicrobiana dos extratos, entretanto, em pequenas concentrações pode-se observar que esta pode estimular o crescimento de bactérias como Escherichia coli, Staphylococcus aureus, Bacillus cereus e Streptococcus faecalis.

As cascas de café, embora em menor concentração quando comparada aos grãos, também apresentam taninos e cafeína. A diferença em quantidade destes compostos depende do modo e eficiência do processamento, variedade da cultura, tipo de solo e condições de cultivo (ELIAS, 1979; PANDEY et al., 2000).

Os resíduos podem conter substâncias reutilizáveis de alto valor agregado, possíveis de serem convertidas em produtos comerciais, através de tecnologias adequadas (LAUFENBERG et al., 2003). Neste sentido, é importante avaliar os compostos presentes nas cascas de café, resíduo agroindustrial abundante no Brasil, visando agregar valor comercial a estes resíduos, utilizados na agricultura como fonte de matéria orgânica, na produção de frangos utilizando as cascas como cama de aviário e alimentação de animais, apesar da baixa digestibilidade.

Sendo assim, o objetivo deste estudo foi realizar a extração dos constituintes das cascas de café, com diferentes solventes e traçar os perfis dos componentes lipofílicos e hidrofílicos, utilizando diferentes técnicas analíticas. Objetivou-se também a identificação de metabólitos de valor comercial e a obtenção de extratos com maior concentração destes metabólitos, além disto o potencial antimicrobiano destes extratos foi avaliado.

\section{MATERIAIS E MÉTODOS}

\section{MÁTERIA-PRIMA E PREPARO DAS AMOSTRAS}

As cascas de café utilizadas para a realização deste estudo foram fornecidas pela Coamo Agroindustrial Cooperativa (Campo Mourão - PR), resultantes do beneficiamento de grãos por via seca. As cascas são provenientes de uma mistura das variedades arábica e conilon plantadas na região do Paraná e de Minas Gerais, da safra de 2015. O material foi homogeneizado e triturado em moinho de facas 
(Solab), com o diâmetro das partículas de 0,85 mm, embalado e armazenado em congelador até a realização dos experimentos.

\section{EXTRAÇÕES POR SOXHLET}

A obtenção dos extratos oleosos das cascas de café foi realizada no sistema de extração Soxhlet com circuito de chapas de aquecimento (Prodicil, Mod. 11.36 L), por 5 horas, utilizando $3 \mathrm{~g}$ de amostra e $200 \mathrm{~mL}$ do solvente selecionado, conforme método proposto por Lim et al. (2010), com modificações na proporção soluto/solvente. Foram empregados cinco diferentes solventes, de grau analítico para a extração: $n$-hexano (Dinâmica 98,5\%), ciclohexano (Dinâmica 99,0\%), diclorometano (Neon 99,5\%), clorofórmio (Proquímicos 99,8\%) e éter de petróleo (Vetec 99,9\%). Os extratos obtidos foram recuperados por evaporação do solvente, acondicionados em frascos e armazenados a $-18{ }^{\circ} \mathrm{C}$, em freezer doméstico. O rendimento de cada extração foi calculado através da Equação 1. Os resultados de rendimento foram avaliados por análise de variância ANOVA a 95\% de confiança através do software Excel.

$$
R(\%)=\frac{m_{\text {extrato }}}{m_{\text {casca }}} x 100
$$

Onde:

$m_{\text {extrato }}(\mathrm{g})=$ representa a massa de fração oleosa obtida na extração;

$m_{\text {casca }}(\mathrm{g})=$ massa de casca de café utilizada na extração em base úmida.

\section{PERFIL DOS EXTRATOS OLEOSOS E IDENTIFICAÇÃO DE CAFEÍNA POR CROMATOGRAFIA GASOSA ACOPLADA À ESPECTROMETRIA DE MASSAS (CG-MS)}

Os extratos oleosos extraídos com diferentes solventes foram analisados por Cromatografia Gasosa acoplada à Espectrometria de Massas (CG-MS). As análises foram realizadas em cromatógrafo a gás acoplado à espectrômetro de massas (Shimadzu GC-2010 Plus), com coluna capilar de sílica fundida modelo Rtx-5MS (Restek, $30 \mathrm{~m} \times 0,25 \mathrm{~mm} \times 0,25 \mu \mathrm{m})$ e injetor split $(1: 50)$ a $245^{\circ} \mathrm{C}$. O volume injetado foi $2,0 \mu \mathrm{L}$. $\mathrm{O}$ gás hélio foi utilizado como gás de arraste. A ionização foi realizada por impacto de elétrons (IE), com voltagem de $70 \mathrm{eV}$ e corrente de emissão de 60 uA. A aquisição dos dados ocorreu no modo SCAN, com monitoramento dos íons de 35 a $300 \mathrm{~m} / \mathrm{z}$. A temperatura na separação foi de $80^{\circ} \mathrm{C}$ durante 6 minutos seguido por um aumento na temperatura de $6{ }^{\circ} \mathrm{C} \cdot \mathrm{min}^{-1}$ até $120{ }^{\circ} \mathrm{C}$, em seguida a temperatura foi aumentada em $30{ }^{\circ} \mathrm{C} \cdot \mathrm{min}^{-1}$ até $215^{\circ} \mathrm{C}$ e finalmente elevada em $6{ }^{\circ} \mathrm{C} \cdot \mathrm{min}^{-1}$ até $240{ }^{\circ} \mathrm{C}$ sendo mantida por 5 minutos, com um total de tempo de corrida de $25 \mathrm{~min}$.

\section{ESPECTROSCOPIA DE INFRAVERMELHO COM TRANSFORMADA DE FOURIER (FTIR)}

Para a análise de FTIR foi utilizada a metodologia descrita por Leimann (2011), com modificações. A identificação de grupos funcionais característicos, na composição dos extratos apolares, obtidos com solventes de diferentes polaridades e seletividades, foi realizada por FTIR. Foram preparadas pastilhas de 
brometo de potássio $(\mathrm{KBr})$ contendo o extrato (óleo) disperso no mesmo. As pastilhas foram analisadas em espectrofotômetro Shimadzu (IR AFFINITY-1). Os espectros foram obtidos na faixa de $4000-400 \mathrm{~cm}^{-1}$ utilizando 32 acumulações e resolução de $4 \mathrm{~cm}^{-1}$. Para comparação da composição dos extratos, foram analisados os espectros de cada óleo obtido.

\section{AVALIAÇÃO DA ATIVIDADE ANTIMICROBIANA DOS EXTRATOS OLEOSOS POR DIFUSÃO EM DISCO}

O método de antibiograma de Kirby e Bauer, de acordo com o protocolo estabelecido pelo documento M100-S19/2009, "Clinical and Laboratory Standards Institute" (CLSI, 2009) foi utilizado, para a avaliação da atividade antimicrobiana dos extratos de baixa polaridade. Para determinação da atividade foram utilizadas placas estéreis contendo Ágar Mueller Hinton com o cultivo recente de bactérias a serem analisadas, sendo elas: Salmonella typhimurium (ATCC 14028), Escherichia coli (ATCC 25922), Staphylococcus aureus (ATCC 25923), Pseudomonas aeruginosa (ATCC 27853) e Bacillus cereus (ATCC 14579). Os discos foram elaborados com papel filtro quantitativo de $125 \mathrm{~mm}$ (Unifil) estéril. Para a embebição dos discos, os extratos oleosos de baixa polaridade obtidos de diferentes solventes foram dissolvidos em seus respetivos solventes e mantidos em fluxo laminar estéril até a evaporação completa do solvente.

Os discos de cada extrato obtido foram colocados sobre a superfície do meio. Por fim, as placas foram encubadas em estufa bacteriológica a temperatura de $37{ }^{\circ} \mathrm{C}$ por 24 horas. Cada teste foi realizado em duplicata. Após o período de incubação, foi avaliada a formação de halos de inibição em torno dos discos (CLSI, 2009).

\section{EXTRAÇÃO DOS COMPOSTOS HIDROFÍLICOS DAS CASCAS DE CAFÉ}

Para a extração dos compostos com maior polaridade das cascas de café foram testadas quatro condições de solvente em dois métodos de extração, utilizando $1 \mathrm{~g}$ de cascas de café para $20 \mathrm{~mL}$ de solvente. Foram utilizadas soluções hidroetanólicas, com porcentagens de 20,40, 60 e $80 \%$ de etanol e a proporção soluto/solvente de 1:20 (m/v). A extração a frio foi realizada à temperatura ambiente $\left(20-25^{\circ} \mathrm{C}\right)$ em tubos tipo Falcon com agitação em um homogeneizador rotativo de tubos (Phoenix, AP 22). A extração a quente foi realizada a $40{ }^{\circ} \mathrm{C}$ no mesmo tipo de tubo utilizando um banho térmico com agitação. As extrações foram realizadas por 24 horas e os extratos foram filtrados em papéis filtro quantitativos (125 mm, Unifil). Imediatamente após a filtração, os extratos foram analisados por cromatografia líquida de alta eficiência (HPLC-DAD).

\section{CARACTERIZAÇÃO DOS EXTRATOS HIDROETANÓLICOS POR HPLC-DAD}

Os extratos foram filtrados através de um filtro de seringa de nylon de 0,22 $\mu \mathrm{m}$ (Millipore, São Paulo, Brasil) e analisados em cromatógrafo líquido Dionex Ultimate 3000 (Dionex, Idstein, Alemanha) acoplado a detector de arranjo de diodos. O software Chromeleon foi utilizado para controlar o amostrador automático, configurar os gradientes e realizar a aquisição de dados. As separações 
foram realizadas em uma coluna Acclaim ${ }^{\circledR} 120, C_{18}, 5 \mu \mathrm{m}, 120 \AA$ (4,6 mm x 250 $\mathrm{mm}$ ), operando a $40^{\circ} \mathrm{C}$ com fluxo de $1,0 \mathrm{~mL} \cdot \mathrm{min}^{-1}$. As fases móveis utilizadas foram uma solução de ácido acético $1 \%$ (Solvente $\mathrm{A}$ ) e metanol (Solvente B) com tempo total de análise de 65 min e gradiente programado como segue: $5-10 \%$ B (0-2 $\mathrm{min}), 10-12 \%$ B (2-3 min), 12-16\% B (3-5 min), 16-23\% B (5-10 min), 23-33\% B (10-20 min), 33-45\% B (20-30 min), 45-65\% B (30-40 min), 65-80\% B (40-45 $\mathrm{min}), 80-100 \%$ B ( $45-50 \mathrm{~min}), 100 \%$ B (50-55 min), 100-5\% B (55-60 min) e 5\% B (60-65 min). Os tempos de retenção e espectros de UV dos compostos presentes no extrato das cascas de café foram comparados aos dos padrões disponíveis no laboratório, sendo estes: ácido gálico, catequina, ácido siríngico, capsaicina, ácido clorogênico, ácido cafeico, ácido p-cumárico, ácido ferúlico, dihidrocapsaicina, rutina, quercetina, teobromina e cafeína. Os padrões foram separados como descrito no gradiente citado acima, otimizado por Rodrigues et al. (2015). As análises foram realizadas em triplicata.

\section{QUANTIFICAÇÃO DA CAFEÍNA NOS EXTRATOS POR HPLC-DAD}

Para quantificação da cafeína nos extratos hidroetanólicos, um novo gradiente foi otimizado, utilizando como fases móveis: solução de ácido acético $1 \%$ (Solvente A) e metanol (Solvente B) para um total de tempo de execução de 32 min. A quantificação da cafeína foi realizada por HPLC-DAD, utilizando o mesmo cromatógrafo descrito anteriormente. $\mathrm{O}$ gradiente foi programado como segue: $30 \%$ B (0-10 min), 30-100\% B (10-12 min), 100\% B (12-20 min), 100-30\% B (20-22 $\mathrm{min}), 30 \%$ B (22-32 min). As separações foram realizadas em coluna Acclaim ${ }^{\circledR} 120, C_{18}, 5 \mu \mathrm{m}, 120 \AA$ (4,6 mm x $\left.250 \mathrm{~mm}\right)$, operando a $40{ }^{\circ} \mathrm{C}$ com vazão de $1,0 \mathrm{~mL} \cdot \mathrm{min}^{-1}$ e deteç̧ão no UV $(\lambda=271 \mathrm{~nm})$. Esse método foi utilizado para determinar a melhor proporção de solvente extrator e tipo de extração para a cafeína. As amostras foram analisadas em triplicata e a média das áreas dos picos foi utilizada para a quantificação.

Para determinação da linearidade foram preparadas soluções para a construção das curvas analíticas através de padronização externa, utilizando-se cafeína padrão comercial ( $98 \%$ de pureza; ISOFAR) nas concentrações de 0,980; 0,$490 ; 0,294 ; 0,196 ; 0,098 ; 0,049 ; 0,025$ e $0,010 \mathrm{mg} \cdot \mathrm{mL}^{-1}$, as análises de cada ponto foram realizadas em triplicata.

O limite de detecção (LD) foi calculado a partir da Equação 2 e o limite de quantificação (LQ) foi determinado pela Equação 3 (RIBANI, 2004; SHRIVASTAVA; GUPTA, 2011).

$$
\begin{array}{ll}
L D=3,3 \times \frac{\mathrm{s}}{\mathrm{s}} & \text { Equação (2) } \\
L Q=10 \times \frac{\mathrm{s}}{\mathrm{s}} & \text { Equação (3) }
\end{array}
$$

Onde:

$s$ = estimativa do desvio padrão do coeficiente linear da equação;

$S=$ inclinação ("slope"), ou coeficiente angular da curva analítica. 


\section{COMPARAÇÃO DO TEOR DE CAFEÍNA EXTRAÍDO DAS CASCAS E DOS GRÃOS DE CAFÉ}

A metodologia de extração que proporcionou o melhor rendimento de cafeína a partir das cascas de café, determinado por HPLC-DAD, foi utilizada para a obtenção de um extrato dos grãos de café, torrados e moídos, para comparação do teor de cafeína nas cascas (resíduos) e grãos de café. O perfil dos extratos fol obtido seguindo a metodologia descrita para a caracterização dos extratos hidroetanólicos por HPLC-DAD. Para a quantificação da cafeína extraída nos grãos de café e comparação com as cascas foi utilizada a metodologia otimizada para a quantificação, utilizando-se $1 \mathrm{~g}$ de café torrado e moído para $20 \mathrm{~mL}$ de solvente extrator. A amostra de café torrada e moída, utilizada para a realização desse estudo, foi adquirida no comércio local da cidade de Campo Mourão, da linha tradicional, da empresa que concedeu as amostras de cascas de café.

\section{DETERMINAÇÃO in vitro DA CONCENTRAÇÃO INIBITÓRIA MÍNIMA (CIM) DO EXTRATO HIDROETANÓLICO DA CASCA DE CAFÉ}

O extrato hidroetanólico das cascas de café obtido pela melhor condição de extração (etanol $40 \%$ ) foi seco em estufa com circulação de ar a $50{ }^{\circ} \mathrm{C}$, em placas de petri, pelo período de 24 horas. Após este período, o extrato foi resolubilizado em $20 \mathrm{~mL}$ de água destilada e congelado em ultra freezer a $-76^{\circ} \mathrm{C}$. Posteriormente, o extrato foi submetido à secagem por liofilização (L101-LIOTOP), a uma pressão de vácuo de aproximadamente $61 \mu \mathrm{Hg}$ a $-53^{\circ} \mathrm{C}$. O produto liofilizado foi embalado e armazenado em frasco plástico em freezer doméstico.

Para avaliação da atividade antimicrobiana do extrato hidroetanólico com melhor teor de cafeína, foi utilizado o método de micro diluição em caldo, de acordo com o protocolo estabelecido pelo documento M100-S22/2012, "Clinical and Laboratory Standards Institute" (CLSI, 2012). Foram preparadas placas estéreis com o cultivo recente das bactérias a serem analisadas, sendo elas: Salmonella typhimurium (ATCC 14028), Escherichia Coli (ATCC 25922) e Staphylococcus aureus (ATCC 25923). Para a determinação da Concentração Inibitória Mínima (CIM), foram feitas diluições seriadas (1:2) do extrato em $100 \mu \mathrm{L}$ de caldo Mueller Hinton Broth (MHB), com uma concentração inicial de $8 \mathrm{mg} \cdot \mathrm{mL}^{-1}$ e final de $0,015 \mathrm{mg} \cdot \mathrm{mL}^{-1}$. As microplacas foram incubadas em estufa bacteriológica (Fanem, Mod. $002 \mathrm{CB}$ ) à temperatura de $35^{\circ} \mathrm{C}$ durante 24 horas.

\section{RESULTADOS E DISCUSSÃO}

\section{EXTRAÇÕES POR SOXHLET}

As extrações por Soxhlet, foram realizadas em triplicata, utilizando solventes de diferentes polaridades. Os rendimentos das extrações e índices de polaridade dos solventes utilizados, de acordo com Collins et al. (2006) e Neto e Nunes (2003), estão apresentados na Tabela 1. 
Tabela 1. Rendimento médio das extrações de óleo utilizando diferentes solventes.

\begin{tabular}{ccc}
\hline Solvente & Polaridade $^{*}$ & Rendimento (\%) \\
\hline éter de Petróleo & 0,00 & $0,78 \pm 0,05$ \\
ciclohexano & 0,04 & $1,19 \pm 0,03$ \\
$n$-hexano & 0,10 & $0,95 \pm 0,09$ \\
diclorometano & 3,10 & $1,26 \pm 0,08$ \\
clorofórmio & 4,10 & $1,55 \pm 0,23$ \\
\hline
\end{tabular}

NOTA: ${ }^{~}$ Índice de polaridade dos solventes em ordem crescente.

Os resultados apresentados na Tabela 1 demonstram que o melhor rendimento médio do extrato bruto encontrado foi obtido utilizando clorofórmio como solvente extrator. Pode-se verificar que não houve diferença significativa ( $p>0,05)$ entre os rendimentos obtidos utilizando os diferentes solventes. Por meio desse método de extração, a temperatura, a reciclagem do solvente e a interação entre o solvente e a matriz vegetal, favorecem a extração de compostos, que de acordo com as características dos solventes, podem apresentar variações no rendimento dos extratos obtidos e composição química (MEZZOMO et al., 2009).

Os solventes quimicamente semelhantes que possuem parâmetros de seletividade similares fazem parte do mesmo grupo, no entanto, podem apresentar diferentes valores de polaridade (POOLE; DIAS, 2000). A partir dos resultados, é possível verificar que os solventes com maiores índices de polaridade apresentaram melhores rendimentos nas extrações. De acordo com os resultados obtidos em um estudo por Andrade (2011), as cascas de café possuem grande quantidade de compostos de média e alta polaridade, sendo que solventes com essas características, como o diclorometano e clorofórmio (polaridade intermediária), podem obter bons rendimentos na extração por Soxhlet.

Comparando o percentual médio de rendimento obtido utilizando o solvente clorofórmio com os rendimentos encontrados na literatura, observou-se que o valor encontrado está entre os resultados obtidos em alguns estudos, como de Brand et al. (2000), por exemplo. No entanto, notou-se que os rendimentos obtidos no presente estudo não foram semelhantes ao encontrado por Andrade (2011) para o extrato oleoso, sendo que a polaridade dos solventes utilizados por esse autor (etanol e acetato de etila), apresentaram melhores rendimentos $(3,4 \mathrm{e}$ $4,8 \%$, respectivamente).

\section{IDENTIFICAÇÃO DE CAFEÍNA NOS EXTRATOS OLEOSOS POR CROMATOGRAFIA GASOSA ACOPLADA À ESPECTROMETRIA DE MASSAS (CG-MS)}

A caracterização dos extratos oleosos obtidos por Soxhlet, utilizando diferentes solventes extratores foi realizada por CG-MS. Pela análise dos cromatogramas e espectros de massas obtidos por CG-MS e comparação dos dados de fragmentação com a biblioteca virtual NIST 21, foi possível identificar a cafeína nos extratos obtidos com diclorometano e clorofórmio, com tempo de retenção $\left(t_{R}\right)$ igual a 19,95 min (Figura 1). Apenas os solventes com características dipolares foram capazes de extrair a cafeína devido à seletividade dos mesmos. 

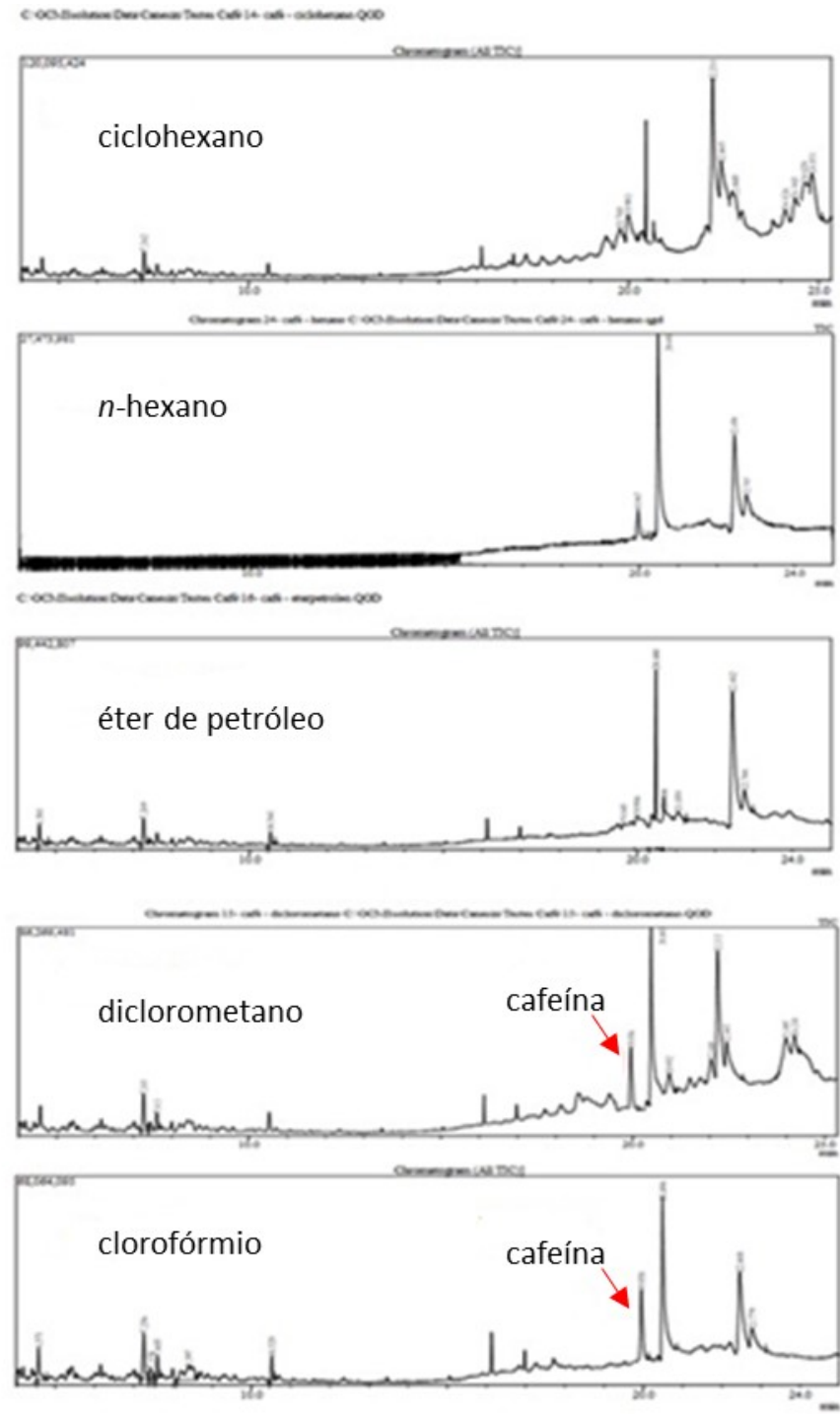

Figura 1. Cromatogramas obtidos por CG-MS (EI) dos extratos oleosos das cascas de café, extraídos por diferentes solventes.

\section{ESPECTROSCOPIA DE INFRAVERMELHO COM TRANSFORMADA DE FOURIER (FTIR)}

Na Figura 2 estão apresentados os espectros de FTIR obtidos para os extratos oleosos das cascas de café por diferentes solventes e na Figura 3 as estruturas químicas da cafeína e do ácido clorogênico, identificados nestes extratos. Na Tabela 2 as bandas de absorção identificadas estão relacionadas com as respectivas ligações da cafeína e/ou ácido clorogênico.

As bandas de absorção no infravermelho características da molécula de cafeína e ácido clorogênico aparecem nos espectros dos extratos obtidos utilizando clorofórmio e diclorometano como solventes de extração (Figura 2). Entre essas bandas, para o ácido clorogênico, identificou-se as bandas referentes a carbonila de éster $\left(1715 \mathrm{~cm}^{-1}\right)$, hidroxila $\left(1316 \mathrm{~cm}^{-1}\right)$, hidroxila referente a estrutura fenólica $\left(3750 \mathrm{~cm}^{-1}\right)$ e ao ácido carboxílico $\left(3400 \mathrm{~cm}^{1}\right)$, além da ligação carbono-carbono $\mathrm{sp}^{2}$ do anel aromático $\left(1516 \mathrm{~cm}^{1}\right)$, permitindo confirmar a estrutura deste composto. Para a cafeína, foram identificadas as bandas de 
carbonila $\left(1715 \mathrm{~cm}^{-1}\right)$, das ligações simples carbono-hidrogênio $\left(2950 \mathrm{~cm}^{-1}\right)$ e dupla carbono-carbono $\left(3116 \mathrm{~cm}^{-1}\right)$, além das bandas características da ligação de aminas (1216 e $1016 \mathrm{~cm}^{-1}$ ) e amidas $\left(1650 \mathrm{~cm}^{-1}\right)$, confirmando a estrutura da cafeína. Os demais espectros não apresentam tais bandas, corroborando com os resultados obtidos por CG-MS.

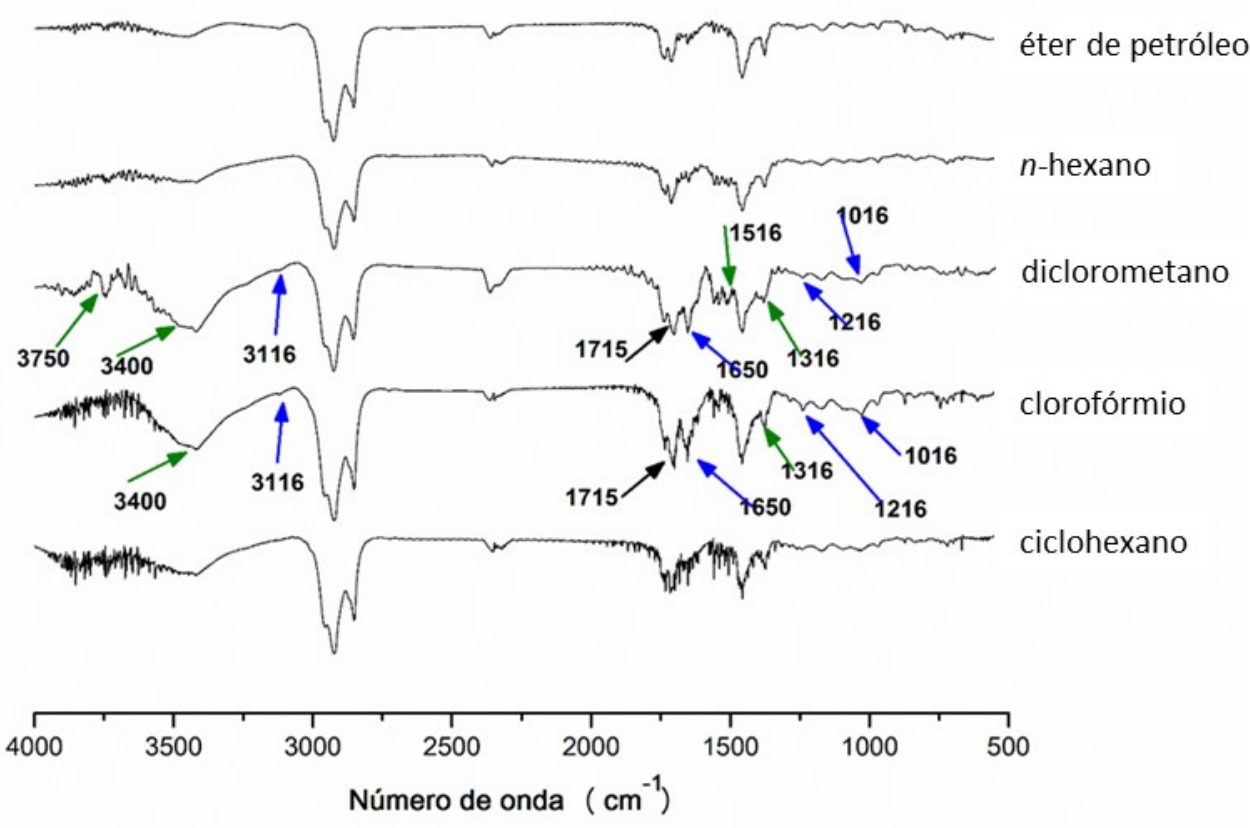

Figura 2. Espectros de FTIR dos extratos da casca de café obtidos com os diferentes solventes orgânicos. As setas em verde indicam as bandas características do ácido clorogênico, em azul da cafeína e em preto as bandas comuns aos dois compostos.<smiles>Cn1c(=O)c2c(ncn2C)n(C)c1=O</smiles>

(a)<smiles>O=C(CCc1ccc(O)c(O)c1)OC1CC2(O)CC(O)C(O)C1C2=O</smiles>

(b)

Figura 3. Estruturas químicas da cafeína (a) e do ácido clorogênico (b).

De acordo com Belay et al. (2008) a literatura indica que o diclorometano e o clorofórmio são úteis para descafeinação de grãos de café, porém estes são solventes tóxicos que podem deixar resíduos no material extraído, além de gerar resíduos após a extração que devem ser tratados de maneira especial para o descarte. O mesmo autor cita que a eficiência do diclorometano para extrair a cafeína a partir de grãos de café é de $98-99 \%$ e que o clorofórmio embora tenha uma boa eficiência de extração tende a extrair uma quantidade maior de compostos interferentes que o diclorometano. 
Tabela 2. Bandas de absorção identificadas nos espectros de FTIR dos extratos de casca de café.

\begin{tabular}{|c|c|c|c|c|}
\hline Composto & Ligação & Banda $\left(\mathrm{cm}^{-1}\right)$ & $\begin{array}{l}\text { Banda da } \\
\text { referência }\left(\mathrm{cm}^{-1}\right) \\
\end{array}$ & Referência \\
\hline \multirow{5}{*}{$\begin{array}{c}\text { Ácido } \\
\text { clorogênico }\end{array}$} & $C=0$ & 1715 & 1692 & \multirow{5}{*}{$\begin{array}{l}\text { (BHATTACHARYYA } \\
\text { et al., 2014) }\end{array}$} \\
\hline & $\mathrm{C}-\mathrm{O}$ & 1316 & 1334 & \\
\hline & $\mathrm{OH}$ fenólico & 3750 & 3860 & \\
\hline & $\begin{array}{l}\text { OH ácido } \\
\text { carboxílico }\end{array}$ & 3400 & 3736 & \\
\hline & $\mathrm{C}=\mathrm{C}$ aromático & 1516 & 1513 & \\
\hline \multirow[t]{6}{*}{ Cafeína } & $C=O$ & 1715 & 1703 & \multirow{6}{*}{$\begin{array}{l}\text { (MOHAMMED; AL- } \\
\text { BAYATI, 2009) }\end{array}$} \\
\hline & $=\mathrm{C}-\mathrm{H}$ & 3116 & 3112 & \\
\hline & $\mathrm{C}-\mathrm{H}$ & 2950 & 2953 & \\
\hline & $\mathrm{C}-\mathrm{N}$ & 1216 & 1236 & \\
\hline & $\mathrm{C}-\mathrm{N}$ & 1016 & 1024 & \\
\hline & $\mathrm{C}=\mathrm{N}$ & 1650 & 1657 & \\
\hline
\end{tabular}

Andrade et al. (2012) realizaram extração de grãos de café já utilizados e cascas de café, por Soxhlet utilizando os seguintes solventes: $n$-hexano, diclorometano, acetato de etila e etanol. Os autores identificaram a presença de ácido clorogênico somente no extrato obtido utilizando acetato de etila. A cafeína foi identificada nos extratos obtidos com $n$-hexano $(2,1 \mu \mathrm{g}$ por $\mathrm{mg}$ de extrato), diclorometano (189,9 $\mu \mathrm{g}$ por $\mathrm{mg}$ de extrato) e etanol (129,6 $\mu \mathrm{g}$ por $\mathrm{mg}$ de extrato). Possivelmente no presente trabalho a cafeína possa ter sido extraída pelos solventes de menor polaridade ( $n$-hexano, ciclohexano e éter de petróleo), porém numa proporção muito menor que pelo clorofórmio e pelo diclorometano, não tendo destaque das bandas características nos espectros em função da baixa concentração.

\section{CARACTERIZAÇÃO DOS EXTRATOS HIDROETANÓLICOS POR HPLC-DAD}

O perfil cromatográfico dos componentes de maior polaridade presentes nas cascas de café foi avaliado por HPLC-DAD. Para a otimização da extração destes constituintes, foram testadas diferentes proporções dos solventes extratores etanol e água (etanol: $80,60,40$ e $20 \%$ ) utilizando um método de extração a frio e a quente.

Etanol e água foram escolhidos como solventes extratores, pois esta opção gera resíduos menos tóxicos do que o uso de metanol, por exemplo. O etanol é considerado um "biosolvente", por ser obtido a partir de fontes renováveis e por ser menos nocivo à saúde dos analistas além de poder ser descartado como resíduo comum (CARDOZO et al., 2013).

García e Del Bianchi (2015) avaliando a capacidade antioxidante de diferentes resíduos do beneficiamento de café. Extraíram compostos fenólicos das cascas de café utilizando acetona e água, identificando e quantificando o ácido clorogênico por HPLC, presente em maior quantidade na casca de café que nos outros resíduos. Mediante os resultados obtidos por HPLC-DAD no presente trabalho, foi possível identificar o ácido clorogênico nos extratos, corroborando com resultados apresentados na literatura. Entretanto, o ácido clorogênico não foi identificado 
como composto majoritário do extrato das cascas de café no presente trabalho, sendo esse fato explicado pela utilização de outra solução extratora (etanol e água). Ainda assim, a obtenção de ácido clorogênico a partir das cascas de café pode ser uma alternativa para a indústria farmacêutica e de alimentos, considerando a atividade biológica desse composto fenólico e agregação de valor ao resíduo agroindustrial (PANDEY et al., 2000; GARCÍA; DEL BIANCHI, 2015).

Avaliando a composição de diferentes extratos de casca de café por HPLC em fase reversa obtidos com acetato de etila e etanol, sob diferentes métodos, Andrade et al. (2012) encontraram para os extratos das cascas de café os seguintes compostos: ácido vanílico, epicatequina, ácido gálico, ácido tânico, ácido protocatecuico e ácido clorogênico, sendo este último o composto fenólico identificado na maioria dos extratos. Os ácidos clorogênicos são os principais componentes fenólicos do café, são solúveis em álcoois de cadeia curta e em misturas álcool-água (AZEVEDO, 2005).

Pode-se observar neste estudo que a mudança na proporção da mistura dos solventes extratores (etanol e água) não resultou em mudanças significativas na composição química dos extratos, porém houve mudança na quantidade extraída do composto majoritário. O composto majoritário com $t_{R}=15,9 \mathrm{~min}$ foi identificado por comparação do tempo de retenção e espectro de UV com o do padrão comercial. A substância majoritária foi identificada como sendo a cafeína. A comparação dos perfis cromatográficos para os extratos obtidos na extração a frio utilizando diferentes proporções de etanol e água por HPLC-DAD $(\lambda 271 \mathrm{~nm})$ estão apresentados na Figura 4.
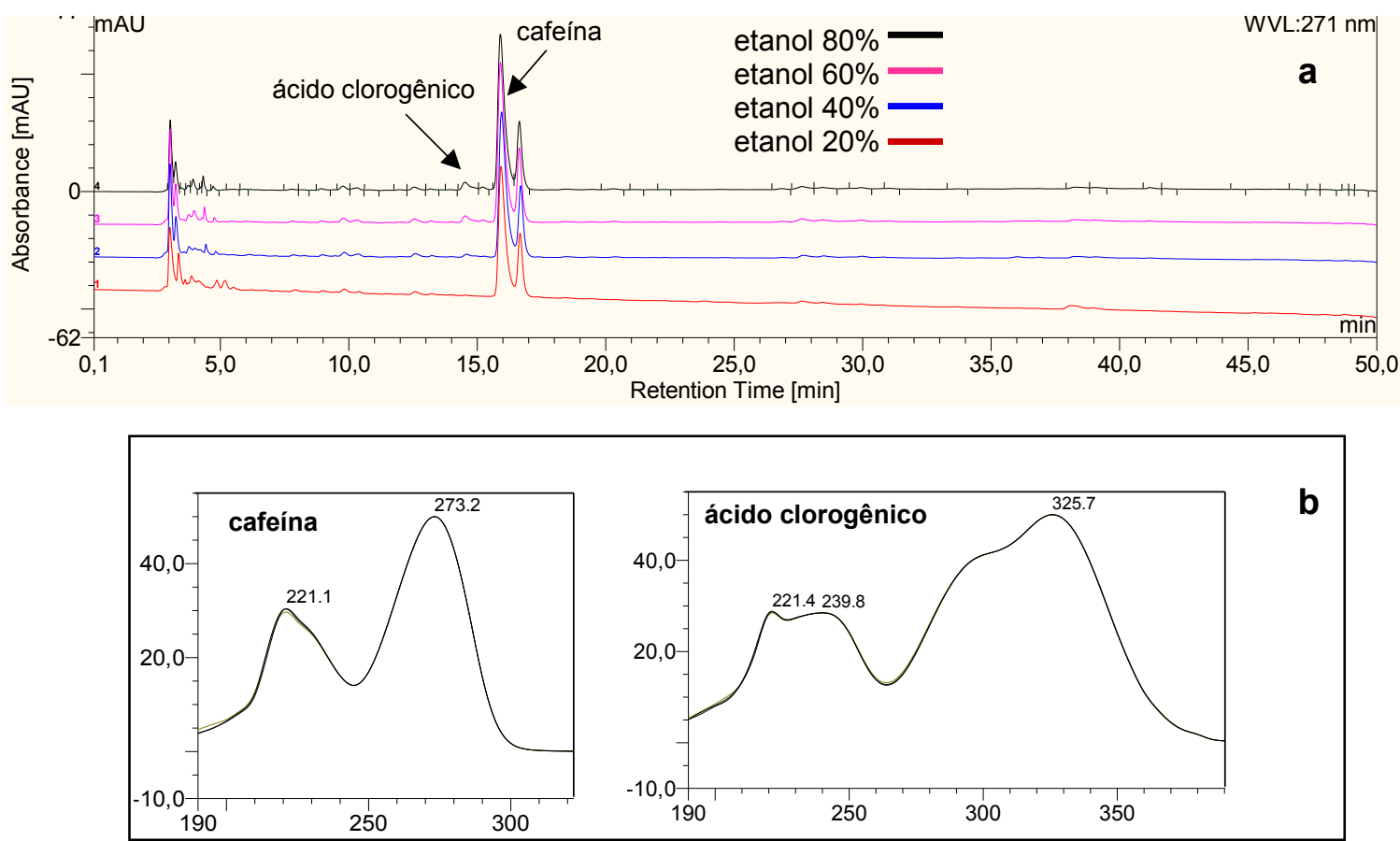

Figura 4. (a) Comparação dos perfis cromatográficos para os extratos obtidos na extração a frio utilizando diferentes proporções de etanol e água por HPLC-DAD ( $\lambda 271 \mathrm{~nm})$. (b) espectros de UV das substâncias identificadas nos extratos. 


\section{QUANTIFICAÇÃO DA CAFEÍNA NOS EXTRATOS POR HPLC-DAD}

Após a identificação da cafeína, como composto majoritário nos extratos obtidos das cascas de café nas extrações a frio e a quente, procedeu-se para a sua quantificação.

A quantificação da cafeína, foi realizada através da construção da curva de calibração externa na faixa de concentração de $0,01 \mathrm{mg} \cdot \mathrm{mL}^{-1}$ a $0,98 \mathrm{mg} \cdot \mathrm{mL}^{-1}$, representada pela equação da reta $y=96,601 x+0,4215$ e com o coeficiente de correlação $\left(R^{2}\right)$ de 0,9998.

O método analítico foi considerado linear na faixa de estudo. Para as concentrações de cafeína testadas e as respectivas áreas dos picos, obteve-se um coeficiente de determinação $\left(R^{2}\right)$ de 0,9998 , o que se caracteriza linear e adequado para tal uso. Com os dados obtidos através da análise de linearidade foi possível calcular os limites de detecção e quantificação, através das equações 2 e 3, respectivamente, tendo sido obtidos os valores de $23,9 \mu \mathrm{g} \cdot \mathrm{mL}^{-1}$ para o limite de deteç̧ão (LD) e 70,1 $\mathrm{gg} \cdot \mathrm{mL}^{-1}$ para o limite de quantificação (LQ).

Comparando a quantidade de cafeína obtida nas extrações a frio e a quente pode-se verificar que as quantidades de cafeína extraídas foram superiores para as extrações a frio, para todas as proporções utilizadas entre etanol e água. Porém utilizando $40 \%$ de etanol obteve-se a maior extração de cafeína, com a concentração de $118 \mu \mathrm{g} \cdot \mathrm{mL}^{-1}$ de extrato (2,36 $\mu \mathrm{g}$ por $\mathrm{mg}$ de casca). A média das áreas dos picos de cafeína em $\lambda=271 \mathrm{~nm}$ e a concentração de cafeína com $t_{R}=6,89$ min obtida nos métodos de extração a quente e a frio se encontram descritos na Tabela 3.

Tabela 3. Quantificação da cafeína ( $\mu \mathrm{g} \cdot \mathrm{mL}^{-1}$ ) extraída utilizando diferentes proporções de etanol e água nos métodos a frio e a quente através da média das áreas dos picos $(n=3)$ da cafeína em $\lambda=271 \mathrm{~nm}$.

$\begin{array}{lll}\text { Q_20\% } & 10,1183 & 100,0 \\ \text { F_20\% } & 10,4114 & 103,1 \\ \text { Q_40\% } & 10,5278 & 105,1 \\ \text { F_40\% } & 11,7865 & 118,0 \\ \text { Q_60\% } & 10,8686 & 108,2 \\ \text { F_60\% } & 11,4665 & 114,1 \\ \text { Q_80\% } & 10,5371 & 105,0 \\ \text { F_80\% } & 11,3918 & 114,2\end{array}$

NOTA: $Q=$ Extração a quente; $F$ = Extração a frio.

Andrade et al. (2012), comparando a quantidade de cafeína extraída por diferentes solventes (diclorometano, $n$-hexano e etanol) e diferentes métodos de extração (ultrassom, Soxhlet e extração supercrítica com dióxido de carbono com e sem adição de etanol) na borra e nas cascas de café, observou que as concentrações de cafeína para o extrato de casca de café foram superiores para todas as condições testadas quando comparada aos extratos da borra de café. 


\section{COMPARAÇÃO DO TEOR DE CAFEÍNA NAS CASCAS E GRÃOS DE CAFÉ}

A cafeína, identificada como a substância majoritária nos extratos hidrofílicos das cascas de café é uma substância com diversas aplicações comerciais, como por exemplo, na indústria alimentícia e farmacêutica (ANDRADE, 2011). Sendo o objetivo deste trabalho caracterizar os constituintes químicos dos extratos lipofílicos e hidrofílicos das cascas de café visando agregar valor a este resíduo do beneficiamento do café, foi realizada a comparação da quantidade de cafeína presente nas cascas e grãos de café, por HPLC-DAD. A comparação foi realizada utilizando a melhor condição de extração da cafeína nas cascas de café, previamente estabelecida como sendo etanol $40 \%$, pelo método de extração a frio. Os cromatogramas dos grãos e cascas de café mostrando a diferença do teor de cafeína extraída destas duas matrizes estão apresentados na Figura 5.

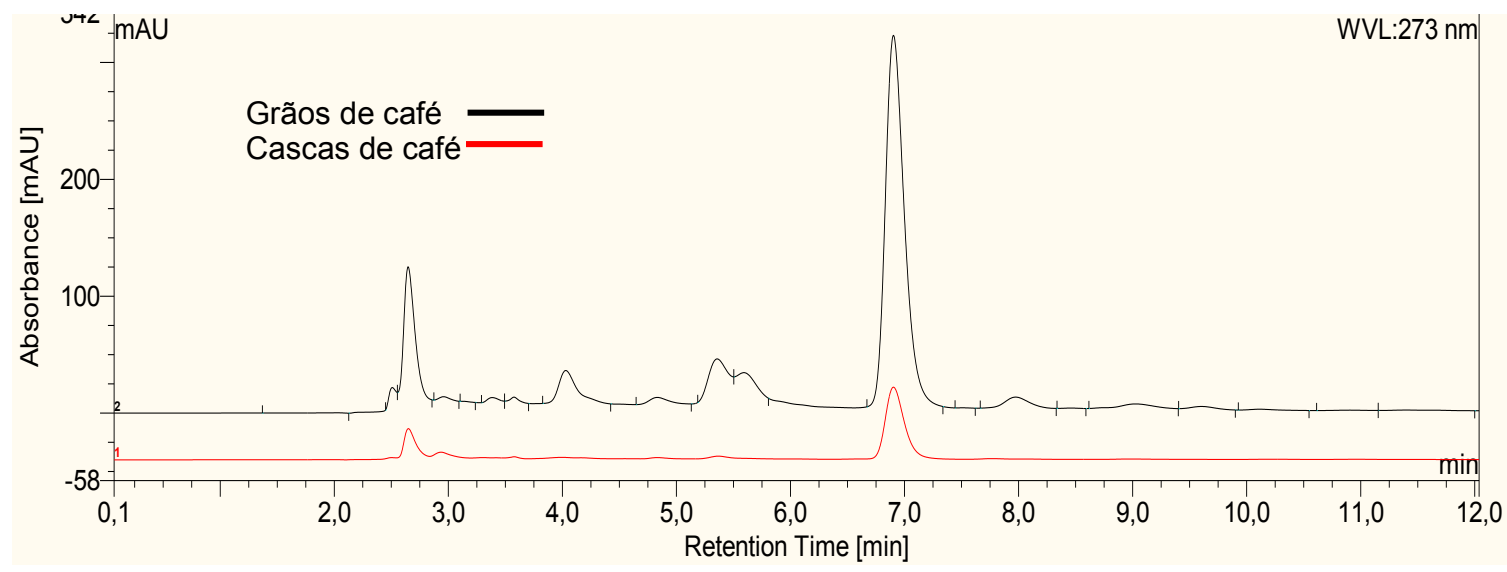

Figura 5. Cromatograma de comparação da quantificação da cafeína nas cascas e grãos de café na melhor condição de extração (etanol $40 \%$ a frio) ( $\lambda 273 \mathrm{~nm}$ ).

Pela quantificação da cafeína extraída na melhor solução extratora, determinou-se uma razão de 1 para 6 , sendo que os grãos apresentaram aproximadamente seis vezes mais cafeína do que as cascas de café. A concentração de cafeína obtida nas amostras de cascas e grãos de café por HPLC-DAD estão apresentadas na Tabela 4.

Tabela 4. Comparação da extração da cafeína utilizando etanol $40 \%$ no método a frio pela média das áreas dos picos $(n=3)$ da cafeína em $\lambda=273 \mathrm{~nm}$ e concentração de cafeína nos diferentes extratos.

Produto da cafeína $\left(t_{R}=6,89 \mathrm{~min}\right)$

\section{Cafeína ( $\left.\mu \mathrm{g} \cdot \mathrm{mL}^{-1}\right)$}
Café em grão
61,5565
634,3
Casca de café
11,7865
118,0

Considerando os diferentes métodos de obtenção de cafeína com utilização de solventes orgânicos como diclorometano, capaz de produzir toxidade aos produtos empregados, o presente trabalho demonstra uma alternativa para a obtenção de cafeína a partir da casca de café, resíduo gerado em quantidade 
apreciável, utilizando solventes menos tóxicos e que causam menos impacto ambiental.

\section{DETERMINAÇÃO in vitro DA ATIVIDADE ANTIMICROBIANA DOS EXTRATOS DAS CASCAS DE CAFÉ}

Como o ácido clorogênico e a cafeína são relatados na literatura como substâncias que apresentam atividade antimicrobiana, o potencial de inibição de microrganismos destas substâncias foi avaliado para os extratos oleosos obtidos por Soxhlet, empregando o método de difusão em disco. Apesar dos relatos na literatura indicarem que essas substâncias possuem atividade antimicrobiana (GARAMBONE; ROSA, 2007; CHAO et al., 2012; CLAUDIO et al., 2013), os resultados obtidos no presente trabalho demostraram que não houve ação inibitória dos extratos oleosos frente aos microrganismos testados. $O$ extrato hidroetanólico que apresentou maior concentração de cafeína (etanol 40\%) também foi testado, porém, utilizando o método de micro diluição. No entanto, não foi observada inibição para nenhum dos microrganismos avaliados, nas concentrações de extrato testadas $\left(8\right.$ a $0,015 \mathrm{mg} \cdot \mathrm{mL}^{-1}$ ).

Todos os microrganismos utilizados nesse estudo (Salmonella typhimurium, Escherichia Coli, Staphylococcus aureus, Pseudomonas aeruginosa e Bacillus cereus) apresentaram resistência aos extratos empregados, não havendo o desenvolvimento do halo de inibição em torno dos discos, tanto para os extratos com a presença de ácido clorogênico e cafeína (obtidos pelo solvente clorofórmio e diclorometano), quanto para os demais extratos ( $n$-hexano, ciclohexano e éter de petróleo). Para o extrato hidroetanólico também não foi possível determinar a Concentração Bactericida Mínima (CBM), pois este não apresentou atividade nas concentrações testadas.

A propriedade de inibição depende de fatores como a cepa de microrganismo testada, do tipo de extrato e da concentração dos princípios ativos (ALMAJANO, et al., 2008). Dessa forma, as concentrações das substâncias presentes nos extratos podem ter sido insuficientes para o efeito de inibição e sugere que concentrações maiores dessas substâncias poderiam apresentar melhores resultados.

\section{CONCLUSÃO}

O presente trabalho avaliou a capacidade de extração por Soxhlet dos constituintes das cascas de café, utilizando diferentes solventes orgânicos. Podese observar que não houve diferença significativa no rendimento dos extratos oleosos obtidos. Porém, a composição química dos extratos obtidos apresentou diferenças quando analisada por FTIR e CG-MS, sendo que apenas os solventes clorofórmio e diclorometano foram capazes de extrair cafeína e ácido clorogênico das cascas de café.

Para a extração dos constituintes mais hidrofílicos das cascas de café foram propostos dois tipos de extração, a quente e a frio, utilizando diferentes proporções de etanol e água. Estes extratos foram avaliados por HPLC-DAD, onde pode-se determinar que as cascas assim como os grãos de café são boas fontes de cafeína. $O$ extrato que apresentou maior rendimento de extração deste composto foi obtido a frio utilizando $40 \%$ de etanol. Ao comparar o teor de cafeína nas cascas 
e grãos, os resultados mostraram que apesar da casca de café apresentar menor concentração de cafeína que os grãos, aproximadamente seis vezes menor, o extrato hidroetanólico da casca apresenta baixa complexidade, o que facilitaria o uso destas na obtenção da cafeína pura, agregando valor a este resíduo vegetal e contribuindo para o aproveitamento dos resíduos produzidos no beneficiamento do café, reduzindo assim o impacto ambiental gerado por seu descarte. Além de propor um método de extração que gera menos resíduos tóxicos por utilizar etanol como solvente, sendo proposta uma metodologia verde para a obtenção de cafeína.

Os extratos obtidos neste estudo não apresentaram atividade antimicrobiana frente aos microrganismos testados. 


\title{
Extraction and characterization of the compounds of coffee husk, an industry residue
}

\begin{abstract}
The residue generated during coffee processing, mainly coffee husks, constitutes approximately $50 \%$ of the coffee production. Looking at this problem, the aim of this study was to obtain extracts of coffee husks using different solvents, evaluate their composition and antimicrobial activity. Using Soxhlet extraction, with solvents of different polarities and selectivities ( $n$-hexane, cyclohexane, dichloromethane, chloroform and petroleum ether), it was possible to observe, using Gas Chromatography-Mass Spectrometry, and Infrared Spectroscopy with Fourier Transformation, the difference in chemical composition of the extracts, being chloroform and dichloromethane the only solvents capable to extract caffeine. The hydrophilic extracts were obtained using different ethanol/water ratios, at room temperature and at $40{ }^{\circ} \mathrm{C}$. Changings in the solvent proportions did not change the chemical profile of the extracts, obtained by High Performance Liquid Chromatography with Diode Array detection, however, changed the amount of caffeine extracted. Caffeine was the major compound extracted and the best conditions was at room temperature using ethanol/water $40 \%(\mathrm{v} / \mathrm{v})$. None of the extracts tested showed antimicrobial activity against the bacteria Salmonella typhimurium (ATCC 14028), Escherichia Coli (ATCC 25922), Staphylococcus aureus (ATCC 25923), Pseudomonas aeruginosa (ATCC 27853) and Bacillus cereus (ATCC 14579). It can be concluded that coffee husks show considerable amount of caffeine and could be used as a source of this compound, contributing to the transformation of this vegetable waste into value added product, reducing the environmental impact generated by the disposal of this toxic residue.
\end{abstract}

KEYWORDS: coffee husks; oily extract; hydroethanolic extract; caffeine; vegetable waste. 


\section{REFERÊNCIAS}

ABIC. Associação Brasileira da Industria de Café. 2016. Disponível em: <http://www.abic.com.br/publique/cgi/cgilua.exe/sys/start.htm?sid=38>. Acesso em: 25 fev. 2016.

ALMAJANO, M. P.; CARBO, R.; JIMÉNEZ, J. A. L.; GORDON, M. H. Antioxidant and antimicrobial activities of tea infusions. Food Chemistry, n. 108, p. 55-63, 2008.

ANDRADE, K. S.; GONÇALVEZ, R. T.; MARASCHINB, M.; RIBEIRO-DO-VALLE, R. M.; MARTÍNEZ, J.; FERREIRA, S. R. S. Supercritical fluid extraction from spent coffee grounds and coffee husks: Antioxidant activity and effect of operational variables on extract composition. Talanta, n. 88, p. 544-552, 2012.

ANDRADE, K. S. Avaliação das técnicas de extração e do potencial antioxidante dos extratos obtidos a partir de casca e de borra de café (coffea arabica I.). 2011. 123 f. Dissertação (Mestrado) - Programa de Pós-Graduação Engenharia de Alimentos, Universidade Federal de Santa Catarina. 2011.

AZEVEDO, A. B. A. Extração e recuperação dos princípios ativos do café utilizando fluidos supercríticos. 2005. Tese (Doutorado em Engenharia Química) Faculdade de Engenharia Química. Universidade Estadual de Campinas. 2005.

BELAY, A.; TURE, K.; REDI, M.; ASFAW, A. Measurement of caffeine in coffee beans with UV/vis spectrometer. Food Chemistry, n. 108, p. 310-315, 2008.

BHATTACHARYYA, S.; MAJHI, S.; SAHA, B. P.; MUKHERJEE, P. K. Chlorogenic acidphospholipid complex improve protection against UVA induced oxidative stress. Journal of Photochemistry and Photobiology B: Biology, n. 130, p. 293-298, 2014.

BRASIL. O Ministério da Agricultura, Pecuária e Abastecimento. Café. 2016. Disponível em: <http://www.agricultura.gov.br/>. Acesso em: 28 fev. 2016.

BRAND, D.; PANDEY, A.; ROUSSOS, S.; SOCCOL, C. R. Biological detoxification of coffee husk by filamentous fungi using a solid state fermentation system, Enzyme and Microbial Tecnology, v. 27, n. 2000, p. 127-133. Disponível em: <http://www.sciencedirect.com/>. Acesso em: 21 mar. 2016.

BRUM, S. S. Caracterização e modificação química de resíduos sólidos do beneficiamento do café para produção de novos materiais. 2007. $138 \mathrm{f}$. 
CARDOZO, K. H. M.; NAKAMURA, O.; ERNESTO, V. A. R. T.; CAVASSIN, E. D.; GONÇALVES, A. S. E.; GIANNETTI, B. F.; CARVALHO, V. M. Aplicação da Química Verde na Análise de Esteroides: Uso do Etanol Para Extração em Fase Sólida como Alternativa Sustentável. International Workshop Advances in Cleaner Production. São Paulo, 2013.

CHAO, J.; WANG, H.; ZHAO, W.; ZHANG, M.; ZHANG, L. Investigation of the inclusion behavior of chlorogenic acid with hydroxypropyl- $\beta$-cyclodextrin. International Journal of Biological Macromolecules, n. 50, p. 277-282, 2012.

CLÁUDIO, A. F. M.; FERREIRA, A. M.; FREIRE, M. G.; COUTINHO, J. A. P. Enhanced extraction of caffeine from guaraná seeds using aqueous solutions of ionic liquids. Green Chemistry, n. 15, 2013.

CLINICAL AND LABORATORY STANDARDS INSTITUTE. (2012). Performance Standards for Antimicrobial Susceptibility Testing; Twenty-Second Informational Supplement. CLSI document M100-S22, Wayne, PA: Clinical and Laboratory Standards Institute, 2012.

CLINICAL AND LABORATORY STANDARDS INSTITUTE. (2009). Performance standards for antimicrobial susceptibility testing. Ninth tenth Informational Supplement. CLSI document M100-S19, Wayne, PA: Clinical and Laboratory Standards Institute, 2009.

COLLINS, C. H. et al. Fundamentos de cromatografia. São Paulo: Unicamp, 2006.

CONAB. Companhia Nacional de Abastecimento. Acompanhamento da safra brasileira: Café. Conab, v. 2, n. 1, p. 1-68. Brasília: jan. 2016. Disponível em: <http://www.conab.gov.br>. Acesso em: 01 mar. 2016.

ELIAS, L. G. Coffee Pulp: Composition, Technology and Utilization. In: J. E., Braham and R., Bressani, R. International Development Research Centre, Ottawa, v. 108e, p. 11-16, 1979.

FARDIAZ, S. Antimicrobial Activity of Coffee (Coffea robusta) Extract. ASEAN Food Journal, v. 10, n. 3, p. 103-106, 1995.

FERNANDES, G. Extração e purificação de cafeína da casca de café. 2007. 107 f. Dissertação (Mestrado) - Programa de Pós-Graduação em Engenharia Química, Universidade Federal de Uberlândia. 2007. 
GARCÍA, L. R. P.; DEL BIANCHI, L. V. Antioxidant capacity in coffee industry residues. Brazilian Journal of Food Technology, v. 18, n. 4, p. 307-313, 2015.

GARAMBONE, E.; ROSA, G. Possíveis benefícios do ácido clorogênico à saúde. Alimentos e Nutrição Araraquara, Araraquara, v.18, n. 2, p. 229-235, 2007.

GONÇALVES, A.L.; FILHO, A. A.; MENEZES, H. Estudo comparativo da atividade antimicrobiana de extratos de algumas árvores nativas. Arquivos do Instituto Biológico, São Paulo, v.72, n. 3, p. 353-358, 2005.

LAUFENBERG, G.; KUNZ, B.; NYSTROEM, M. Transformation of vegetable waste into value added products: (A) the upgrading concept; (B) practical implementations. Bioresourse Technology, n. 87, p. 167-198, 2003. Disponível em: <http://www.sciencedirect.com/>. Acesso em: 26 mar. 2016.

LEIMANN, F. V. Nanopartículas híbridas de polímero natural (phbv)/polímero sintético. 2011. Tese (Doutorado) - Universidade Federal de Santa Catarina. Santa Catarina, 2011.

LIMA, G. S.; MANHÃES, J. H. C.; PESSOA, T. N.; MIGUEL, D. L.; SIMÕES, M. L. G. Utilização de casca de café como substrato para produção de celulase por Trichoderma spp. VIII Simpósio de pesquisa dos cafés do brasil. Salvador, 2013.

LIM, H. K.; TAN, C. P.; KARIM, R.; ARIFFIN, A. A.; BAKAR, J. Chemical composition and DSC thermal properties of two species of Hylocereus cacti seed oil: Hylocereus undatus and Hylocereus polyrhizus. Food Chemistry, n.119, p. 1326$1331,2010$.

MEZZOMO, N. MARTÍNEZ, J.; FERREIRA, S. R. S. Supercritical fluid extraction of peach (Prunus persica) almond oil: Kinetics, mathematical modeling and scale-up. The Journal of Supercritical Fluids, v. 51, n. 1, p. 10-16, 2009.

MOHAMMED, M. J.; AL-BAYATI, F. A. Isolation, identification, and purification of caffeine from Coffea Arabica L. and Camellia Sinensis L.: A combination antibacterial study. International Journal of Green Pharmacy, p. 52-57, 2009.

NETO, F. R. A.; NUNES, D. S. S. Cromatografia: princípios básicos e técnicas afim. Rio de Janeiro: Interciência, 2003.

PANDEY, A.; SOCCOL, C. R.; NIGAMC, P.; BRAND, D.; MOHAN, R.; ROUSSOS, S. Biotechnological potential of coffee pulp and coffee husk for bioprocesses. 
POOLE, C. F.; DIAS, N. C. Practitioner's guide to method development in thin-layer chromatography. Journal of Chromatography, A, 892: p. 123-142, 2000.

Disponível em: <http://ac.els-cdn.com/>. Acesso em: 15 jul. 2016.

RIBANI, M.; BOTTOLI, C. B. G.; COLLINS, C. H.; JARDIM, I. C. S. F.; MELO, L. F. C. Validação em métodos cromatográficos e eletroforéticos. Química Nova, v. 27, n. 5, p. 771-780, 2004.

RODRIGUES, V. C.; SILVA, M. V.; SANTOS, A. R.; ZIELINSKI, A. A. F.; HAMINIUK, C. W. I. Evaluation of hot and cold extraction of bioactive compounds in teas, International Journal of Food Science and Technology, v. 50, p. 2038-2045, 2015.

SHRIVASTAVA, A.; GUPTA, V. B.; Methods for the determination of limit of detection and limito $f$ quantification of the analytical methods. Chronicles of Young Scientists. v. 2, p. 21-25, 2011.

USDA. United States Department of Agriculture. Foreign Agricultural Service. Coffee Summary. fev. 2015. Disponível em: <http://apps.fas.usda.gov/>. Acesso em: 25 fev. 2016.

YOSHIDA, L. M. Extração de solúveis da casca do café torrado. 2005. 223 f. Dissertação (Mestrado) - Programa de Pós-Graduação em Engenharia Química, Universidade Federal de Uberlândia. 2005.

ZOCA, S. M. Avaliação da liberação de potássio por resíduos do benefício do café. 2012. 57 f. Dissertação (Mestrado) - Faculdade de Ciências Agronômicas, Universidade Estadual Paulista. 2012. Disponível em: <http://www.pg.fca.unesp.br/Teses/PDFs/Arq0789.pdf>. Acesso em: 18 mar. 2016.

Recebido: 04 ago. 2017

Aprovado: 22 out. 2017

DOI: $10.3895 /$ rebrapa.v8n2.6887

Como citar:

BAQUETA, M. R. et al. Extração e caracterização de compostos do resíduo vegetal casca de café. Brazilian Journal of Food Research, Campo Mourão, v. 8, n.2, p. 68-88, abr./jun. 2017. Disponível em:

https://periodicos.utfpr.edu.br/rebrapa

Correspondência:

Michel Rocha Baqueta

Universidade Tecnológica Federal do Paraná, Câmpus Campo Mourão, Campo Mourão-PR, Brasil.

Direito autoral: Este artigo está licenciado sob os termos da Licença Creative Commons-Atribuição 4.0 Internacional. 